\title{
PVCURVE: A Computer Spreadsheet Template for Evaluating Pressure- volume Curves
}

\author{
Robert M. Augé \\ Department of Ormamental Horticulture and Landscape Design, P. O. \\ Box 1071, University of Tennessee, Institute of Agriculture, Knoxville, \\ TN 37901-1071 \\ Additional index words. osmotic potential, turgor, water relations
}

Pressure-volume (PV) analysis is often considered to give the most accurate estimate of symplastic osmotic potential (Tyree and Jarvis, 1982). Additional information about tissue water relations can also be computed from PV curves: estimates of bulk cell wall elasticity, symplastic water volume, and turgor potential at various states of tissue water content. The generation of PV curves is a time-consuming procedure, however, and involves considerable computation. Computer programs of varying sophistication that attempt to model the PV relation have been described before (Schulte and Hinckley, 1985). This article describes a computer spreadsheet template for traditional evaluation of a PV curve through linear regression of the zero turgor segment. The template allows real-time plotting of the inverse $\psi /$ water loss relation derived with "expressed sap" or "bench-top drying" protocols, provides estimates of most commonly calculated PV characteristics, and permits instant graphic visualization of changes in water potential components with changes in water potential, total tissue water, and symplastic water content. An acquaintance with spreadsheet software and a thorough understanding of pressure-volume theory on the part of the user is assumed.

The template is organized into six discrete portions, each-occupying roughly one screen of the spreadsheet and accessed with a keystroke. The first portion identifies the sample and lists water relations information at each level of tissue hydration in the PV curve. Once balance pressures, incremental sample fresh weights, final sample dry weight, and clingfilm weight (if used) are entered into appropriate cells, a macro allows quick calculation of total water loss, inverse balance

Received for publication 30 Mar. 1990. I gratefully acknowledge the assistance of Ann Stodola in proofing the template. Mention of the name of a proprietary product is not to be construed as a recommendation of the product as superior to others that may be available. The cost of publishing this paper was defrayed in part by the payment of page charges. Under postal regulations, this paper therefore must be hereby marked advertisement solely to indicate this fact. pressure, relative water content, relative osmotic (or symplastic) water content, volume of symplastic water, water potential, turgor potential, and osmotic potential at each stage of tissue hydration. The inverse balance pressure/tissue water loss relation is automatically plotted, allowing the user to view the PV curve as it develops and to select points (3 to 12) in the zero turgor, linear segment of the plot for linear regression. This first portion of the template records the regression information: number of points regressed, regression and correlation coefficient, slope, and $\mathrm{x}$ and $\mathrm{y}$ intercepts. Each new regression replaces the previous one; in this way, several regressions may be performed within seconds and the best-fit line selected (based on the predetermined criteria of the investigator).

The second portion lists most of the characteristics commonly calculated in PV analysis (Table 1). Routine decisions regarding which PV characteristics can be meaningfully derived from a particular PV curve are still the responsibility of the investigator; drawbacks of PV analysis (Cheung et al., 1976; Tyree and Richter, 1981a, 1981b) are not eliminated or reduced by the program. The template's chief utility is in hastening calculations and graphics. The remaining portions of the template show a legend of macros (which simplify spreadsheet movements and computations), macro definitions, regression calculations, and a table of those points used in the most recent regression. One macro allows selection of graphs that portray total water potential and each water potential component as a function of relative tissue water content or relative osmotic water content. Finally, a macro is given that extracts PV information for each curve and organizes it for insertion into a summary template.

Templates have been written for IBMcompatible machines with Quattro (Borland, Seotts Valley, Calif.) for PV analysis using either a pressure chamber or psychrometer. (The psychrometer template contains a calibration subtemplate and converts WV readings into water potential values.) Templates may be obtained by sending $\$ 3.00$ to me to cover diskette, mailer, and postage.

\section{Literature Cited}

Cheung, Y. N. S., M.T. Tyree, and J. Dainty. 1976 Some possible sources of error in determining bulk elastic moduli and other parameters from pressure-volume curves of shoots and leaves. Can. J. Bet. 54:758-765.

Schulte, P.J. and T.M. Hinckley. 1985. A comparison of pressure-volume curve data analysis techniques. J. Expt. Bet. 36:1590-1602.

Tyree, M.T. and P.G. Jarvis. 1982. Water in tissues and cells, p. 35-77. In: O.L. Lange, P.S. Nobel, C.B. Osmond, and H. Ziegler (eds.). Encyclopedia of plant physiology 12B: Physiologicalplantecology 11. Springer-Verlag, New York.

Tyree, M.T. and H. Richter. 1981a. Alternative methodsofanalyzing water potential isotherms: Some cautions and clarifications. I. The impact of non-ideality and of some experimental errors. J. Expt. Bot. 32:643-653.

Tyree, M.T. and H. Richter. 1981b. Alternative methodsofanalyzing water potential isotherms: Some cautions and clarifications. H. Curvilinearity in water potential isotherms. Can. J. Bot. 60:911-916.

Table 1. An example of the summary screen within the PVCURVE template: characteristics computed from a PV curve constructed from a rose root sample using a pressure chamber.

\begin{tabular}{|c|c|c|c|}
\hline $\begin{array}{l}\text { Total sample water = } \\
\text { Fresh weight @ full turgor= } \\
\text { Water potential @ full turgor = } \\
\text { Osmotic potential @ full turgor = } \\
\text { Turgor potential @ full turgor = } \\
\text { Water content @ full turgor = } \\
\text { Water potential @ turgor loss (calc)= } \\
\text { Water potential @ turgor loss (meas)= } \\
\text { Turgid/dry weight ratio = } \\
\text { Relative dry weight }= \\
\text { RWC @ turgor loss }= \\
\text { ROWC @ turgor loss }= \\
\text { Lowest RWC plotted }= \\
\text { Symplastic water percentage }= \\
\text { Apoplastic water percentage }= \\
\text { N (total } \mu \text { osmol/sample) }= \\
\text { N/g symplastic water }= \\
\text { N/g total water }= \\
\text { N/g sample fresh wt }= \\
\text { N/g sample dry wt }= \\
\end{array}$ & $\begin{array}{c}0.7237 \\
0.9060 \\
-0.05 \\
-0.54 \\
0.49 \\
79.9 \\
-0.82 \\
-0.83 \\
5.0 \\
25.2 \\
67.0 \\
65.7 \\
21.9 \\
96.1 \\
3.9 \\
152.2 \\
218.9 \\
210.4 \\
168.0 \\
835.1 \\
\end{array}$ & 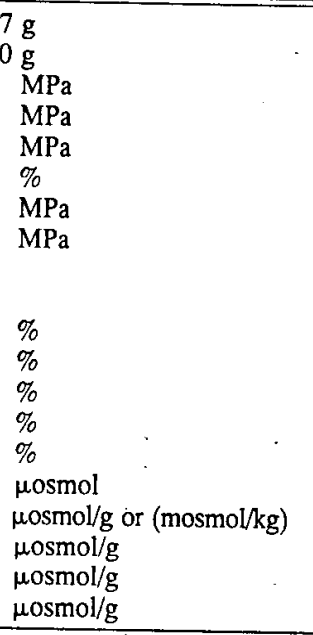 & $\begin{array}{l}\text { Press Home to } \\
\text { return to start } \\
\text { of spreadsheet. }\end{array}$ \\
\hline
\end{tabular}

